\title{
MALDI TOF imaging mass spectrometry in clinical pathology: A valuable tool for cancer diagnostics (Review)
}

\author{
JÖRG KRIEGSMANN $^{1-3}$, MARK KRIEGSMANN ${ }^{4}$ and RITA CASADONTE ${ }^{3}$ \\ ${ }^{1}$ MVZ for Histology, Cytology and Molecular Diagnostics, Trier; ${ }^{2}$ Institute for Molecular Pathology; \\ ${ }^{3}$ Proteopath GmbH, Trier; ${ }^{4}$ Institute for Pathology, University of Heidelberg, Heidelberg, Germany
}

Received August 6, 2014; Accepted November 4, 2014

DOI: $10.3892 / \mathrm{ijo} .2014 .2788$

\begin{abstract}
Matrix-assisted laser desorption/ionization (MALDI) time-of-flight (TOF) imaging mass spectrometry (IMS) is an evolving technique in cancer diagnostics and combines the advantages of mass spectrometry (proteomics), detection of numerous molecules, and spatial resolution in histological tissue sections and cytological preparations. This method allows the detection of proteins, peptides, lipids, carbohydrates or glycoconjugates and small molecules. Formalin-fixed paraffin-embedded tissue can also be investigated by IMS, thus, this method seems to be an ideal tool for cancer diagnostics and biomarker discovery. It may add information to the identification of tumor margins and tumor heterogeneity. The technique allows tumor typing, especially identification of the tumor of origin in metastatic tissue, as well as grading and may provide prognostic information. IMS is a valuable method for the identification of biomarkers and can complement histology, immunohistology and molecular pathology in various fields of histopathological diagnostics, especially with regard to identification and grading of tumors.
\end{abstract}

\section{Contents}

1. Introduction

2. Technical considerations

3. MALDI IMS as an adjunct to immunohistochemistry

4. Frozen vs. formalin-fixed paraffin-embedded tissue samples and analysis of tissue microarrays

5. Identification of peptides and proteins

6. Tumor heterogeneity

7. Tumor margins

8. Tumor typing

Correspondence to: Professor Jörg Kriegsmann, MVZ for Histology, Cytology and Molecular Diagnostics Trier, Max-Planck Strasse 5, D-54296 Trier, Germany

E-mail:kriegsmann@patho-trier.de

Key words: molecular pathology,MALDI, imaging mass spectrometry, pathology
9. Grading and prognosis

10. Identification of drugs and metabolites

11. MALDI IMS in various organs or tissues

12. Summary

13. Perspectives

\section{Introduction}

Matrix-assisted laser desorption/ionization (MALDI) timeof-flight (TOF) techniques are versatile analytical tools used in various areas of medical diagnostics and basic research. Mass spectrometry (MS) has been successfully applied to study microbiological colonies (1-3), plants (4), insects (5), vertebrates including whole animals $(6-8)$, human cells $(9,10)$ and tissues $(11,12)$.

This method allows the analysis of proteins $(13,14)$, peptides $(15,16)$, lipids or phospholipids $(6,17-19)$, carbohydrates or glycoconjugates (20) and exogenous or endogenous small molecules, especially molecules involved in drug metabolism (21-27).

MALDI imaging mass spectrometry (IMS), first described by Caprioli et al (28), links molecular evaluation of numerous analytes and the high sensitivity and selectivity of mass spectrometry with morphological information about spatial distribution of molecules in cells or tissues (29) and thereby provides unbiased visualization of the arrangement of biomolecules in tissue (30).

Since cancer tissue contains all information on proteomic and genetic changes, it represents the best possible sample material for any molecular research (29). Thus, pathology is not only a large field of medical research but also a basis for the diagnosis of various diseases with direct impact on clinical treatment decisions. The information contained in tissues cannot be replaced by investigation of serum or blood (29).

MALDI IMS has been applied to various organ systems and diseases such as cardiovascular- (31), neurologic- (32), or joint disorders $(11,33)$, amyloidosis $(34)$ inflammatory bowel diseases (35), renal diseases (36-38), the field of reproductive medicine (39) and various tumor entities (13,15,40-45). The following review will focus on MALDI IMS in human tumor tissues as well as applications that have a potential in pathology (22). 


\section{Technical considerations}

Despite some technical limitations, mainly in the area of detection limits and instrument sensitivity at high spatial resolution, this method has the potential to improve cancer diagnostics (42). There are several reviews addressing the complete process of MALDI IMS, in particular regarding experimental considerations: sample collection, sample preparation, matrix deposition, ionization process, instrumentation and data processing $(22,30,31,46-54)$.

IMS experiments can generally be performed in two related modes, imaging (57) and profiling (58). Whereas imaging allows correlation with histology, profiling is generally used when tissues are completely homogeneous and, therefore, different compartments do not have to be considered.

Concerning sample collection and sample preparation, workflow solutions have to be exactly defined beginning from the handling of various tissues in the operation theatre, followed by dehydration and paraffin-embedding process as well as deposition of sections onto conductive slides.

Sample handling and preparation are critical to achieve good spectral quality and reproducibility. In the past few years, several groups have worked on strategies to improve the detection of peptides and proteins $(55,56)$; however, optimization and standardization in clinical application to minimize variability of results are still needed.

IMS requires minimal sample preparation for analysis (59). In the past years, there has been a significant improvement in image spatial resolution that is in the range of 20-50 $\mu \mathrm{m}$ and can be improved to up to $5 \mu \mathrm{m}$ with special techniques $(60,61)$.

Data processing and statistical analysis are of tremendous importance for accurate and reliable results. In the processing step MALDI datasets are typically subjected to smoothing, baseline correction and calibration. Normalization is generally the next step intended to minimize the experimental variation arising from day-to-day instrument fluctuations, or artifacts related to sample preparation (62). Statistical analysis is then performed in order to elucidate spectral features that are consistently associated within a cohort for biomarker discovery or for disease classification. Most statistical methods can be performed using a supervised method requiring at least two groups of spectral data that need to be discriminated or an unsupervised analysis applied without any prior knowledge of the samples to generate a classification model. Principal component analysis (PCA) is a well known method used to describe the variability in the dataset in a reduced number of dimensions (63). The software for data analysis, such as ClinProTools and SCiLS Lab (Bruker Daltonik), MassLynx (Waters) and BioWorks (Thermo Fisher Scientific) is usually commercially available and provided by the manufacturer of the MALDI instruments. In addition, BioMap software (Novartis, Basel, Switzerland) is freely available for calculating basic statistics of the full dataset. Despite the different data analysis approaches that have been developed, there is a need for more advanced biostatistical software in order to be able to handle huge data files (5,000-50,000 spectra).

A new and emerging application is the three-dimensional illustration of organ structures. It has been shown that MALDI IMS can be combined with other imaging modalities such as positron emission tomography (PET) and magnetic resonance imaging (MRI), improving the interpretation of the proteomic data and providing 3D visualization of proteins that may not be apparent with other imaging methods $(64,65)$.

Another promising development represents MS for single cell analysis to determine protein and peptide contents in cells (47).

Combination of MALDI IMS with cytological preparations of oral brush biopsies has been shown by Remmerbach et al (9). These authors could discern non-malignant from malignant cells by MS. Furthermore, IMS could be applied as a specific diagnostic tool for routine cervical cytology specimen (10). Thus, IMS as a relatively new technique is still at an early stage, and technical advances concerning sample preparation and instrumentation will certainly improve specificity and sensitivity and enlarge the potential for further applications.

\section{MALDI IMS as an adjunct to immunohistochemistry}

Contrary to antibody-based methods, target structures do not need to be known when MALDI IMS is applied (52) which makes it a valuable discovery tool, since broad range of proteins may be surveyed simultaneously (67).

Furthermore, MS techniques may have a higher reproducibility between laboratories than immunohistochemistry because human bias is abolished (68).

However, MALDI IMS cannot only be an adjunct tool to immunohistochemistry but also to histochemistry. For examle, it has been shown that the Berlin-blue reaction for the detection of hemosiderin can be replaced by MALDI IMS of ferritin chains (33). Likewise, mucous substances detected by histochemical reactions could be identified applying MS (69) as well as soft tissue constituents (70-72).

\section{Frozen vs. formalin-fixed paraffin-embedded tissue samples and analysis of tissue microarrays}

The investigation of frozen tissues by MALDI IMS requires immediate freezing, storage at $-80^{\circ} \mathrm{C}$ and rapid cutting (48) enabling the study of proteins, drugs or their metabolites and lipids. Formalin-fixed paraffin-embedded (FFPE) tissues have to be digested and, therefore, allow analysis of peptides only (Fig. 1). Although frozen samples are easier to be analyzed and imaged as they do not require multiple steps for sample preparation (deparaffination and antigen retrieval), handling and storage of frozen specimens has disadvantages, since proteins are degraded during repeated freeze-thaw cycles and there is a need for expensive freezers.

Despite the difficulties in sample handling, numerous reports have described the application of MALDI IMS on whole sections $(12,13,43,44,57,73-78)$ and even on small biopsy samples of fresh frozen tissue (79).

Millions of FFPE tissues of various diseases including numerous cancer tissues are available in the archives of institutes of pathology. These samples are well documented and include information on patient treatments, treatment response, disease progression and other relevant clinical data (51).

One of the advantages of using fixed specimens is that FFPE tissues are well suited for tissue microarray (TMA) construction, where multiple FFPE core biopsies can be assembled in a single paraffin block. The direct analysis of FFPE TMA using 


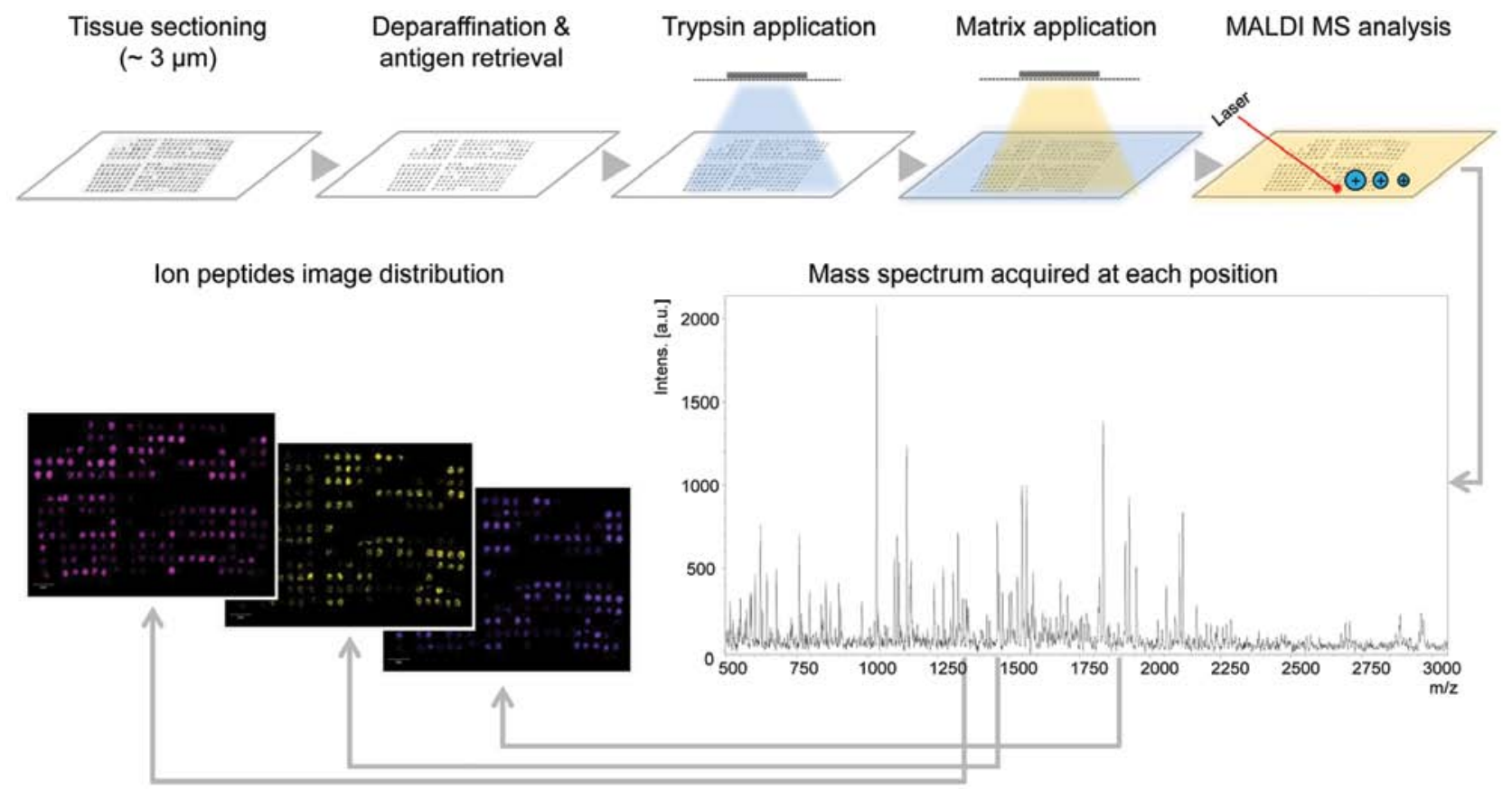

Figure 1. Representative workflow for imaging mass spectrometry of FFPE tissues. The workflow incorporates deparaffination, antigen retrieval steps, ontissue trypsin digestion, matrix application and mass spectrometry signal acquisition. Images of the molecular species of the tryptic peptides can be produced from multiple regions in the section.

MALDI IMS allows the analysis of multiple tissue samples in a single experiment $(67,80)$. This high-throughput method was used to investigate gastric (16), pancreatic (81), non-small cell lung (67), prostate (82), renal cancer (15) and to discriminate pancreatic from breast cancer tissues (83). The correlation of MALDI IMS data with histology can be performed by two methods: either by staining a serial section with hematoxylin and eosin (H\&E) (67) or by staining the tissue after the MALDI experiment, since the tissue is not destroyed during the laser ionization process (47).

\section{Identification of peptides and proteins}

There are many techniques used in the study of proteins, such as western blot analysis, liquid chromatography and reverse phase protein arrays (84-87).

The most common approach to identify proteins using MS technique is the bottom-up approach achieved through protein separation/isolation, proteolytic digestion, sequencing of peptides by LC-MS/MS, and matching the peptides to genome-based protein databases (88-90). Another approach is top-down, where proteins of interest are isolated from a complex protein mixture and directly fragmented in the mass spectrometer without previous digestion of proteins. This approach provides direct measurement of the molecular masses of the intact proteins $(91,92)$. An alternative method for protein identification is on-tissue digestion, where tissue samples are in situ digested so that proteins of interest can be isolated and directly fragmented from the tissue section using MALDI MS/MS. This method offers the advantage to identify proteins from a tissue section without separation or homogenization, while preserving the spatial integrity of the tissue sample $(30,67)$. However, protein identification directly from tissue is not always straightforward due to sample complexity and limited sample per unit area, unless peptides are present at high abundance in the sample. Recently, an imageID approach has been developed where consecutive tissue sections are processed in parallel to provide both, protein identification by LC-MS/MS and spatial information by MALDI IMS simultaneously (83) (Fig. 2). New public databases for the identification of proteins such as MSiMass list (93) and MaTisse (94) have been created enabling users to search either for proteins or for $\mathrm{m} / \mathrm{z}$ values and assign identities to the peaks observed in their experiments. Such databases will improve implementation of MSI in the histopathological and clinical setting.

\section{Tumor heterogeneity}

The biology of a tumor depends not only on tumor cells but also on the interaction with stroma, blood vessels and the immune system (e.g. tumor-associated macrophages and lymphocytes). Homogenization of the tissue sample would lead to loss of information (29). Moreover, when considering personalized medicine, demonstration of tumor heterogeneity (Fig. 3) will be one of the most challenging issues in the future and MALDI IMS seems to be the ideal tool to solve this problem $(29,40,95)$. As an alternative to MALDI IMS in complete tissue sections, captured cells can be mounted directly onto a MALDI target following microdissection thereby maintaining the spatial conformation for IMS (72). DNA- and RNA-based molecular methods have limitations to show tumor heterogeneity since spatial integrity is destroyed during the preparation process of the nucleic acids.

The potential application of MALDI IMS in a clinical workflow has been suggested by Caprioli (96) who stated in 2005 that this method may aid in diagnosis, prognosis and therapy of cancer bringing a new dimension of molecular information into pathological assessment of tissue specimen. 


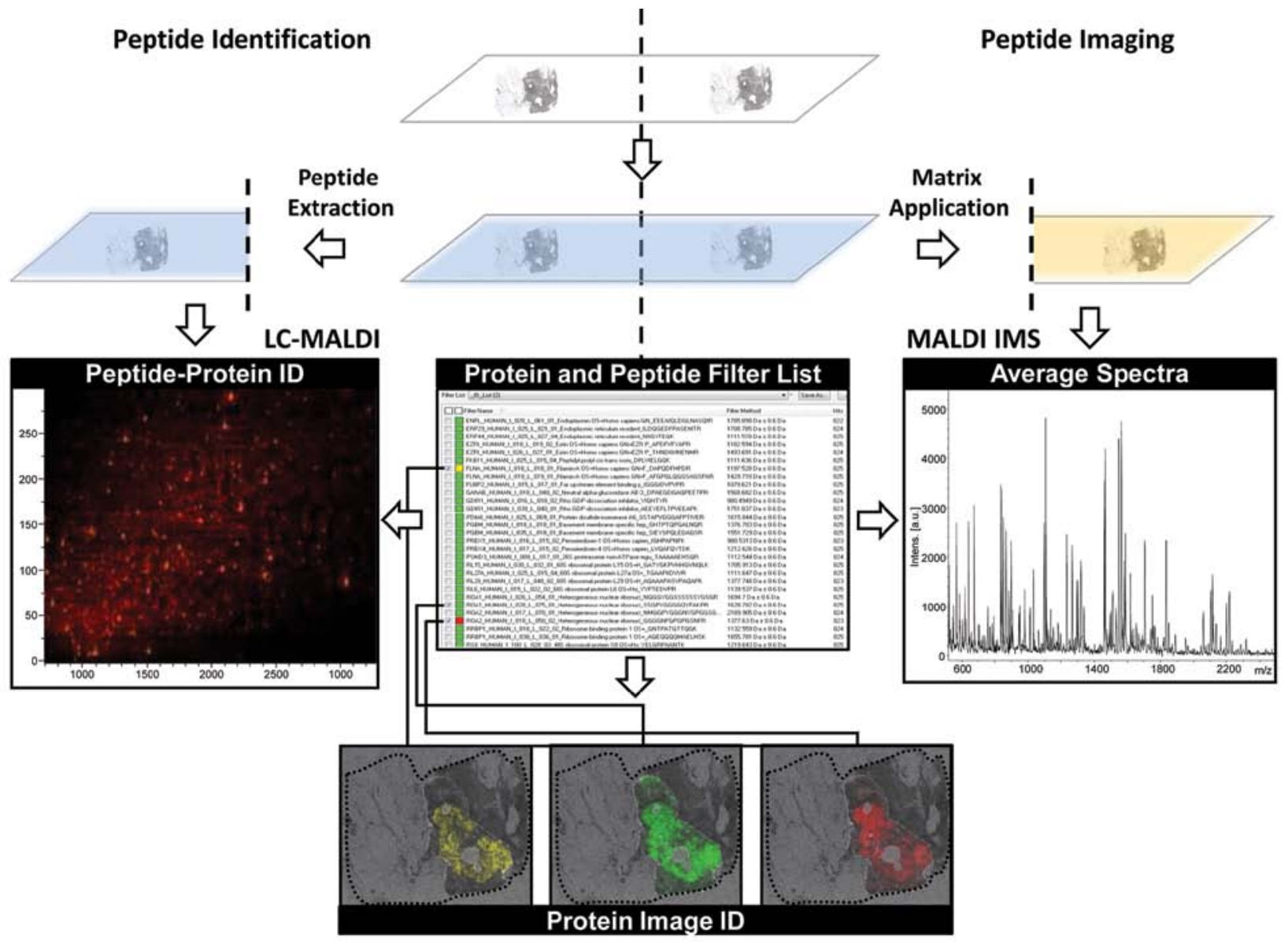

Figure 2. ImageID workflow. Serial tissue sections were processed in parallel to provide both protein identification and distribution simultaneously. On-tissue trypsin digestion was performed in each section under identical conditions. Peptide imaging by MALDI IMS (right side of the figure) provides an image peptide list, whereas peptide identification by LC-MALDI-TOF/TOF analysis (left side of the figure) provides peptide and protein IDs. ImageID software merged the IDs with the image peptide list to the ImageID protein and peptide filter list to establish protein distributions in the tissue. Protein distributions could be visualized and validated based on several peptides that match the particular protein.

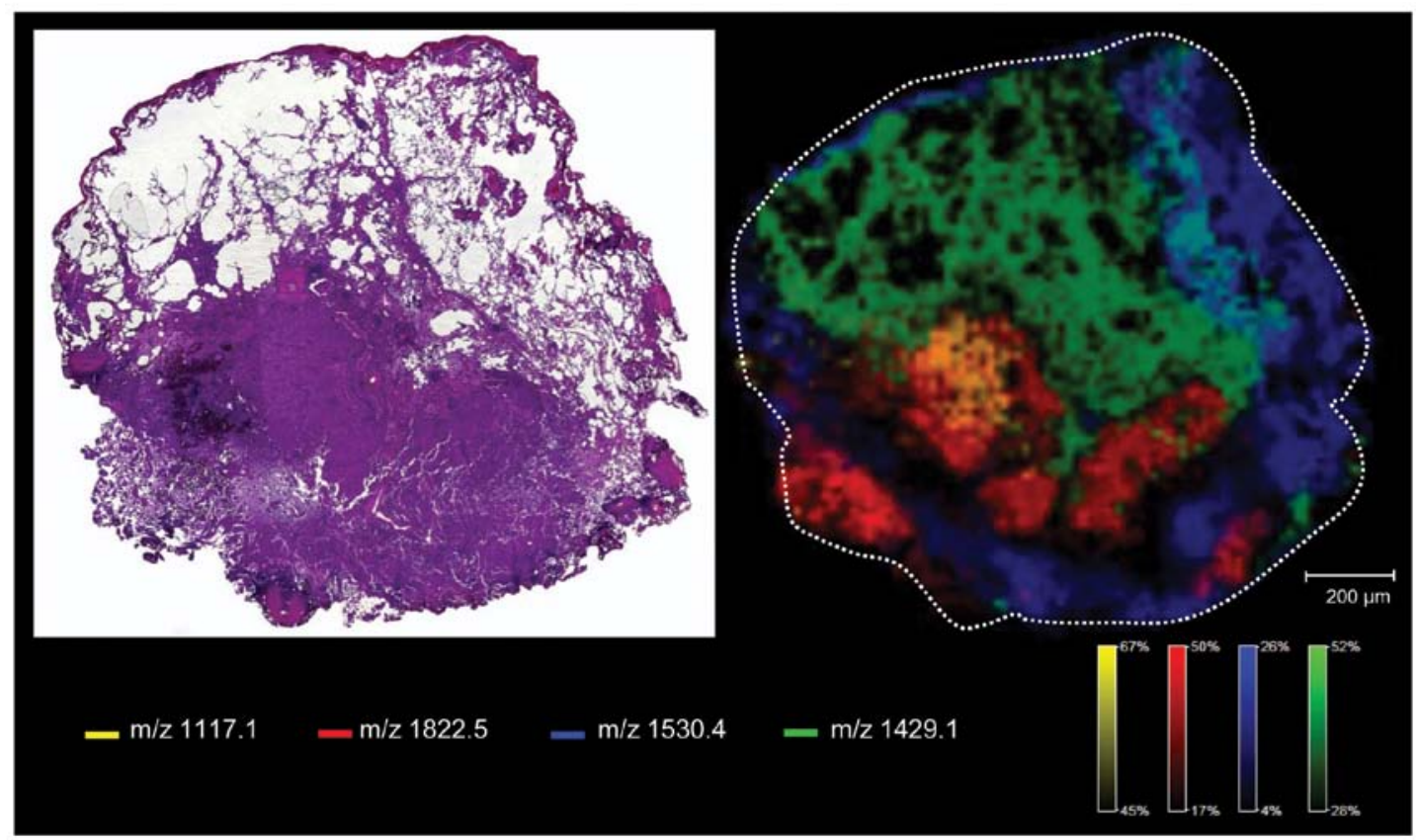

Figure 3. MALDI IMS of one lung cancer tissue section displaying different areas defined from distinct molecular contents in the tissue. (left) Hematoxylin and eosin staining of the section after MALDI acquisition. (right) Combined image of four masses defining a fibrotic region with tumor cells (m/z 1117.1, yellow), a tumor region (m/z 1822.5, red), a non-tumor region (m/z 1530.4, blue), and an area with peritumoral inflammation (m/z 1429.1, green). Images were acquired with a lateral resolution of $200 \mu \mathrm{m}$. 
Today, nearly 10 years later, MALDI IMS is considered a powerful technique to evaluate tumor margins, and to acquire information on tumor typing, grading, prognosis and prediction.

\section{Tumor margins}

MALDI IMS is an objective method to demonstrate molecular tumor margins (resection borders). This was first proposed by Chaurand et al (97). Evidence has shown that adjacent tissue that appears histologically normal may already be molecularly compromised. For example, it has been shown in tumors of the ovary that MALDI analysis could detect two interface-specific proteins, plastin 2 and peroxiredoxin 1 as differentially expressed in the interface zones between tumors and normal tissues, suggesting these proteins as predictive markers for the presence of residual disease (98). Another study on tumor margins was conducted on kidney samples by Oppenheimer et al (44). These authors demonstrated that cells without phenotypic characteristics of tumor cells, have malignant molecular features. Specifically, mass spectral profiles were compared among four different regions of tissue consisting of tumor, margin-tumor, margin-normal and normal. Two statistical methods, the significance analysis of microarrays (SAM) and permutation t-test, were used in this work demonstrating the presence of patterns resembling tumor in the margin-normal microenvironment outside of the histological tumor border. For example, proteins involved in the mitochondrial electron transport system were consistently underexpressed in the tumor as well as in the histologically normal tissue adjacent to the tumor. Another application of MALDI MS dealing with surgical tumor margins has been shown on liver tissue (99). These investigators detected molecular signatures as classifiers of non-tumor and tumor regions that could be applied to the interface between normal liver tissue and hepatocellular carcinoma.

Thus, a potential advantage of IMS for the evaluation of tumor margins is the ability to identify molecular changes that are not detectable by histopathological evaluation alone (47).

\section{Tumor typing}

Numerous antibodies are often required for the correct diagnosis of a tumor. In the future, pathologists will be confronted more frequently with small biopsies since minimally invasive methods have been emerged in the past. Hence, effective and tissue sparing molecular techniques are important for correct classification of tumors. Despite the introduction of multiantibody stains in immunohistochemistry, numerous tissue sections are often required for tumor typing. Since only one tissue section is needed when MALDI IMS is applied, this technique is perfect for the evaluation of very small tissue samples, and the remaining tissue is available for further molecular classification such as mutation screening (e.g. in lung tumors).

The combination of MALDI IMS for tumor classification with typing, grading and subsequent application of MALDI TOF techniques for mutation screening would be a very fast, sensitive and cost efficient workflow able to reduce human bias.
Published results indicate that MALDI IMS has the potential to develop into a valuable diagnostic technique that can complement established histological and histochemical as well as immunohistochemical methods. Biomarkers or signal classifiers can be robustly reproduced in different biomedical centers (73).

MALDI IMS for tumor typing has been demonstrated on frozen (13) as well as on FFPE tissue (16,67). It has been shown that classification of 6 common tumor entities was possible using frozen tissue sections (13). Furthermore, squamous carcinoma and adenocarcinoma of the lung (67), papillary and clear cell renal cancer (15) and gastric carcinoma (16) have been subclassified.

\section{Grading and prognosis}

MALDI IMS has been successfully used to identify subsets of markers that correlate with cancer progression in several cancers including non-small cell lung cancer (76) and pre-invasive bronchial lesions (43), brain tumors $(21,101)$, breast (58), ovarian (102), renal cancer (15), Barrett's adenocarcinoma (103), intestinal-type gastric cancer (78), prostate carcinoma (104) lymph node metastasis of melanoma (105), prostate cancer (82), colonic cancer (13), papillary thyroid carcinoma (14) and urothelial neoplasia (106).

The accuracy to discriminate normal, pre-invasive and invasive lung tissues obtained by MALDI IMS was $>90 \%$ (43).

MS studies have also been used to determine tumor grading. In myxoid sarcomas high-grade tumors could be separated from low-grade tumors. Likewise, MS/MS technique revealed signals specific for poorly differentiated gastric cancer (16).

Additionally, proteomic tissue profiling improved the grading of non-invasive papillary urothelial neoplasia (106). Variation in the protein expression pattern of low-grade and high-grade gliomas could also be demonstrated $(107,108)$.

Besides grading, IMS has been employed to identify early stage disease (79) as well as predictive proteomic signatures for lymph node metastasis in gastric cancer (109). Since hypoxia is related to poor survival and increased frequency of metastasis, one study investigated hypoxia associated proteinpatterns and identified around 100 proteins that may serve as prognostic markers (81). Notably, one group could also show MALDI IMS as a tool to identify peptide signals to predict tumor response to molecular targeted therapy in a breast cancer mouse model (110). All of these applications have a great potential to find their way into routine diagnostics, as methods are needed that reduce human bias.

\section{Identification of drugs and metabolites}

IMS has been used to study drug localization in human tissues as well as in animal models (54,111-119). The visualization and quantitative analysis of the native drug distribution by IMS techniques with enhanced resolution and sensitivity is desirable for evaluating drug effects and optimizing drug design as it has been shown for paclitaxel in tumor-bearing mice (118). Fresh frozen tumor sections from mice bearing BxPC3 pancreatic cancer xenografts, were analyzed by MALDI IMS and LC-MS after paclitaxel (PTX)-incorporating micelle (NK105) administration (50 or 
$100 \mathrm{mg} / \mathrm{kg}$ ) at various time-points (15 $\mathrm{min}, 1,24,48$ and $72 \mathrm{~h}$ ). These sections were compared with tumor sections from mice treated with PTX alone at the same time-points as well as untreated mice. MALDI IMS demonstrated that NK105 successfully delivered a large amount of the PTX within the tumor tissue after NK105 injection compared with PTX injection alone. Quantification of PTX and NK105 were evaluated by LC-MS analysis of the extracted drugs from serial tissue sections for MALDI IMS. The content of the PTX released from NK105 was significantly higher and retained for a longer period of time than the free PTX and control (untreated), suggesting that the antitumor activity of NK105 is superior to that of PTX alone. The high sensitivity and selectivity of IMS combined with visualization of molecular spatial distribution in tissue provides a valuable platform in targeted drug and untargeted metabolomic analysis in biological and clinical research (115). IMS is useful in the comparison of different ways of drug delivery to organs and tissues (120).

Another application is the identification of drugs and their metabolites in the primary or metastatic tumor tissue (112). Furthermore, IMS allowed the characterization of the distribution of small molecules in the microenvironment of tissue compartments of tumors isolated from lung cancer patients and rat xenograft tissues (111). Three experimental models were described in the present study for measuring drug localization. In the 'concentration gradient model', an entire solid xenograft tumor (lung adenocarcinoma A549) tissue was immersed in a solution of the drug mixture containing tiotropium and erlotinib for $2.5 \mathrm{~h}$. A passive transfer of the drug mixture into solid tissue samples displayed a decreasing concentration gradient toward the center of the tissue. In this model investigators wanted to show the efficiency of transport of drugs through various cell types. For example, the signal intensity of drugs from tumor cells was substantially lower than that from stroma. In the 'dispersion model', $10-\mu \mathrm{m}$ tissue section of resected lung adenocarcinoma specimens were immersed into the drug solution, where either adsorption or adsorption/absorption occurred. In this model, the distribution of erlotinib localized well to the area of tumor cells identified by the pathologist. Finally, in the 'directed dosage model' a drug solution was evenly deposited in small spots $(\sim 150 \mu \mathrm{m}$ in diameter) on the tissue surface of adenocarcinoma tumors using a microdispenser-based spotter apparatus. As in the previous model, the localization of erlotinib was found in tumor areas.

As tumor tissue can be resected during the course of therapy, IMS is suitable for the evaluation of treatment efficacy and the therapy may be optimized (113).

\section{MALDI IMS in various organs or tissues}

To enable readers of the present review a fast overview on application of MALDI IMS to tumor tissue, Table I provides a brief summary of the different studies and findings.

Brain. There are only a few studies applying IMS in neurobiological science. The reasons for this include limited access to the technology, relatively low sample throughput and difficult sample preparation. However, MS techniques have been applied to a variety of brain tumors including oligodendrogliomas, astrocytomas, meningiomas and gliomas $(100,108,121,122)$. The technique was used in the differential diagnosis, defining the tumor margins, the assessment of the tumor grade and to distinguish different survival groups. Schwartz et al (101) developed a peptide-based profile that could sub-classify gliomas according to different histologic grades on human brain biopsies. Moreover, a short-long and long-term survival-group could be distinguished by the investigators, using the weighted flexible compound covariate method (WFCCM). A proteomic signature of 24 different MS signals discriminated between patients from a shortterm survival group (52 patients with a mean survival of $<15$ months) and a long-term survival group (56 patients with a mean survival of $>90$ months). These results were also verified as an independent predictor of patient survival using a multivariate Cox proportional hazards model.

IMS has great potential in exploring biomolecular mechanisms underlying disorders. An IMS study developed a preliminary proteomic algorithm that could discriminate meningioma, glioma and non-tumor tissue, although the number of patients was very small (122). In the present review, investigators used support vector machine models able to classify meningioma spectra using a training set built from: i) a single brain tumor class that compared both glioma and meningioma with non-tumor tissue (including blood); ii) a meningioma brain tumor class and non-tumor brain class; and iii) a meningioma class, a glioma class, and a non-tumor brain class. Training sets were built based on the gold standard of WHO histopathology classification of tumors of the central nervous system. Another group was able to discern glioblastoma and oligodendroglioma tumor biopsies by MS but not by IMS (121).

In conjunction with proteomic approaches to assess brain tumors, lipidomic signatures could also provide beneficial information regarding diagnosis, grading and the resection margins (100). Furthermore, pharmacokinetics and pharmacodynamics studies have been performed. Salphati et al (119) visualized and compared the distribution of PI3K inhibitors in glioblastoma multiforme in mouse brain by IMS. Drug transit through the blood-brain barrier (BBB) is essential for therapeutic response in malignant glioma and was studied by IMS (114). In this review, three examples of drug transit through the BBB were reported in mouse brain. Drugs and/or drugs metabolites (BKM120, RAF265 and erlotinib) were imaged in mouse brain tissue sections together with heme, used as a molecular marker delineating the lumen of blood vessels in the brain. In all cases, drugs were found to penetrate the BBB. Specifically, RAF265 and erlotininb were localized within tumor regions, whereas BKM120 distributed in the brain parenchyma. Notably, drugs distributed independently of the heme signal, indicating the escape of the drug molecules from the tumor vasculature.

Breast. MALDI IMS has been applied in breast cancer tissue $(58,74,83,123)$. Additionally, other proteomic mass spectrometric techniques contributed to new insights into breast cancer pathogenesis and prognosis (reviewed in ref. 124). Dijda et al (63) used human breast tumor tissue for the optimization of the protocol for detection of peptides in FFPE sections. 
Table I. Outline of MALDI MS-based studies and findings in the field of cancer research.

Tissue type/ organ/entity

Authors (ref.)

Brain Peptide and protein patterns of primary glial brain tumors and

Schwartz et al (108) non-tumor tissue; discrimination of increasing tumor grade

Identification of protein pattern of gliomas, which could predict short-term and long-term survival (prognosis)

Grading of meningioma based on different protein pattern

Classification of brain tumors based on lipid information; discrimination of meningioma from gliomas

Demonstration of drug transit of small molecules through the blood-brain barrier

Visualization of brain and tumor distribution of PI3K-inhibitors in models of glioblastoma

Breast MALDI IMS of normal breast tissue, ductal carcinoma in situ, invasive breast cancer and peritumoral stroma

Optimized tissue preparation for obtaining peptide mass spectrum profiles from FFPE tissue of breast cancer

Visualization of proteins specific for ductal carcinoma in situ and invasive ductal carcinoma (different stage of the disease)

Determination of lymph node status of breast carcinoma and prediction of response to chemotherapy

Localization of choline metabolites and cations in viable and necrotic tumor regions in a breast cancer xenograft model

Novel approach that combines MALDI-IMS and principal component analysis for generating tumor classification

Protein identification to predict Her2-status of breast carcinomas-identified cysteine-rich intestinal protein 1

IMS of acylcarnitines, phosphatidylcholines, and sphingomyelin in breast tumor models

Discrimination of breast and pancreatic carcinoma based on the peptide profile

Comparison of protein signals of intratumoral and extratumoral stroma in breast cancer; interlaboratory comparison of spectra

Schwartz et al (101)

Agar et al (122)

Eberlin et al (100)

Liu et al (114)

Salphati et al (119)

Cornett et al (58)

Ronci et al (123)

Seeley and Caprioli (34)

Seeley and Caprioli (125)

Amstalden van Hove et al (127)

Djidja et al (63)

Rauser et al (74)

Chughtai et al (128)

Casadonte et al (83)

Dekker et al (73)

Gastrointestinal tract

Oral IMS of biopsy specimen of oral squamous cell carcinoma with reproducible images

Esophagus Detection of COX7A2, TAGLN2 and S100-A10 as prognostic markers in Barrett's adenocarcinoma

Stomach Distinguished gastric cancer from normal mucosa; signals overexpressed in tumor were defensins and calgranulins; stage of disease could be predicted TMA with classification of signals which could discern between normal gastric tissue and adenocarcinoma; signal specific to poor differentiation corresponds to histone $\mathrm{H} 4$

Identification of prognostic seven protein signature in intestinal-type gastric cancer

Identification of S100A8 and S100A9 as negative regulators for lymph node metastasis of gastric cancer

Colon Classification algorithm of six common tumors; liver metastasis of colonic cancer was identified

Lipid signatures in biopsies of liver metastases of colonic cancer IMS of platinum-based metallodrugs in colorectal and ovarian cancer

Patel et al (129)

Elsner et al (103)

Kim et al (79)

Morita et al (16)

Balluff et al (78)

Choi et al (109)

Meding et al (13)

Thomas et al (130)

Bianga et al (113)

Grüner et al (77)

Pancreas Discrimination of $\mathrm{m} / \mathrm{z}$ species of normal pancreas, intraepithelial neoplasia, and intraductal papillary mucinous neoplasms 
Table I. Continued.

Tissue type/

organ/entity

Content of the study/findings

Authors (ref.)

Gastrointestinal tract

Pancreas TMA peptide profiles to discriminate pancreatic from breast cancer

Casadonte et al (83)

Imaging of glucose-regulated protein in pancreatic adenocarcinoma

Djidja et al (81)

Liver

Demonstration of protein profiles of hepatocellular carcinoma and liver cirrhosis

Le Faouder et al (75)

Lung

Classification of protein peaks according to lung cancer histology;

distinguished primary tumor from metastases, discrimination of patients with good and poor prognosis (frozen tissue)

Predictive accuracy of over $90 \%$ of normal tissue, preinvasive lesions and

Yanagisawa et al (76) invasive lung cancer based on proteomic profiles of proteins in frozen sections

TMA of lung tissues with distinction of adenocarinoma and squamous cell carcinoma of the lung by peptide pattern; identification of peptides

Non-small cell cancers, classified according to the MALDI lipid profile

Erlotinib and gefitinib and tiotropium were localized in their microenvironment

Lymphoma Discrimination of Hodgkin's lymphoma and lymphadenitis with a sensitivity and specificity of $83.92 \%$ and $89.37 \%$ by IMS

Skin Detection of protein signatures for survival and recurrence in malignant melanoma Differentiation of Spitz nevi from Spitzoid malignant melanoma by IMS Identification of vemurafenib in malignant melanoma and provided evidence of colocalization of drug and target

Thyroid Identification of S100A10, thioredoxin, and S100-A6 as biomarkers of papillary thyroid carcinomas with lymph node metastasis

Detection of ribosomal protein $\mathrm{P} 2$ specific for papillary thyroid cancer

Good reproducibility of IMS data on cytological samples to distinguish different thyroid lesions; characterization of the proteomic profile of medullary thyroid carcinoma

Urogenital tract

Kidney Analysis of tumor margins in renal cell carcinoma

Detection of race specific profiles in Wilms' tumors

Discrimination of papillary and clear cell renal cancer using TMA samples, prediction of tumor survival

Bladder Proteomic tissue profiling improved grading of non-invasive papillary urothelial neoplasia

Evaluation of signals associated with tumor aggressiveness, histologic phenotype (growth pattern), and cell proliferation in bladder cancer

Ovary Investigation of the interface between serous ovarian carcinoma and normal tissue Identification of a fragment of the $11 \mathrm{~S}$ proteasome activator complex and $\operatorname{Reg} \alpha$ fragment as biomarkers for ovarian carcinoma

Platinum anticancer imaging in ovarian carcinomas

Integrated transcriptomic and lipidomic analysis of sulfatides in ovarian cancer

Presentation of a tryptic peptide reference dataset for IMS on FFPE ovarian cancer tissues

Prostate Discrimination of cancerous from non-cancerous prostatic tissue based on protein profile obtained by IMS

Identification of cancer and non-cancer tissue on the basis of specific fragment of mitogen-activated protein kinase/extracellular signal regulated kinase

Detection of signals associated with favorable tumor phenotype, prolonged time to PSA relapse; multiple signals associated with the ERG-fusion status and with ERG expression

Sarcomas Identification of proteins and lipids in myxoid sarcomas specific to tumor type and grade; could show intra-tumor heterogeneity

Oppenheimer et al (44)

Axt et al (139)

Steurer et al (140)

Oezdemir et al (106)

Steurer et al (140)

Kang et al (98)

Lemaire et al (102)

Bianga et al (113)

Liu et al (141)

Meding et al (142)

Schwamborn et al (41)

Cazares et al (143)

Steurer et al (82)

Willems et al (40) 


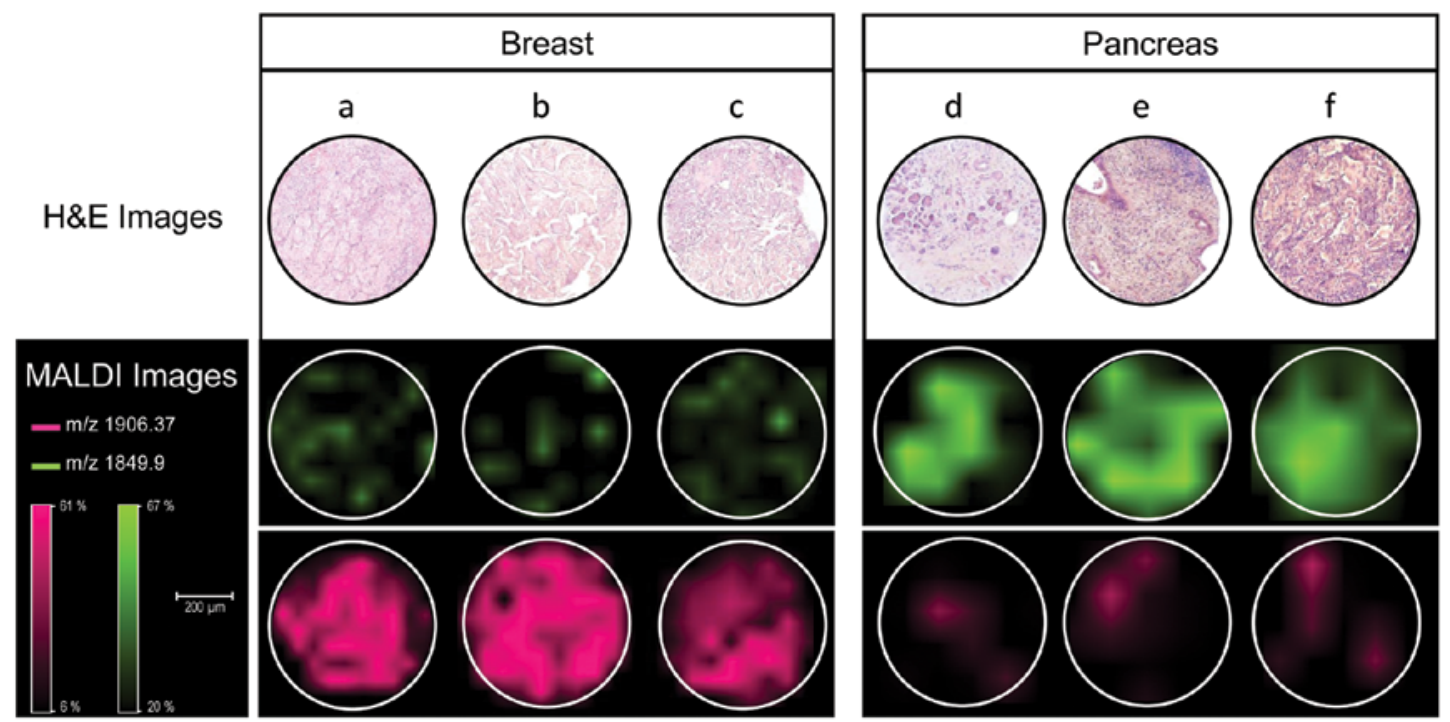

Figure 4. Comparison of histology and MALDI IMS results. H\&E stained section and mass spectral images are showed for breast (a-c) and pancreas (d-f) cancer biopsy samples. Distribution of two m/z peptides, 1906.37 (identified as heat shock protein $\beta$-1, HSPB 27) and 1849.9 (identified as SH3 domain-binding glutamic acid-rich-like protein, SH3L1) differentially expressed between breast and pancreas carcinoma core biopsies. Ion density map of HSB 27 protein show an exclusive distribution to a subset of breast biopsies (a-c), whereas SH3L1 is highly expressed in pancreas biopsies (d-f). H\&E stains were performed after MALDI analysis.

Cornett et al (58) described an automated workflow integrating histopathology and breast tissue profiling of various components in breast cancer tissue. A further IMS analysis of human breast cancer sections revealed three proteins to be specifically localized in different regions of the cancer tissue (34). IMS of metastatic breast cancer in a lymph node found protein signals specifically localized in histologically defined regions (34). An IMS study comparing breast primary tumors from patients with or without lymph node involvement highlighted six differently expressed proteins that could predict lymph node status (125). Besides efforts to elucidate prognostic biomarkers, also predictive profiles have been identified. In a study of breast cancer patients IMS has been shown as a new tool for HER2/neu receptor analysis (74). This is of special interest since at present HER2 amplification status is determined by immunohistochemistry or in situ hybridization or both. These methods suffer from subjective interpretation as well as from high costs and are time-consuming (126).

Dekker et al (73) were able to demonstrate mass signals for stromal activation in breast carcinoma. Furthermore, IMS has been utilized to assess the distribution of lipids in breast cancer showing that heterogeneity is not only restricted to the proteome $(127,128)$.

Since most metastases are adenocarcinomas it might be challenging for the pathologist to determine the origin of the primary tumor. Casadonte et al (83) developed an algorithm to discriminate metastases of breast and pancreatic cancer by MALDI IMS (Fig. 4).

Gastrointestinal tumors. Various studies have addressed MALDI IMS of gastrointestinal tumors including typing, grading and prognosis $(13,16,35,75,77,79)$.

Oral. MALDI IMS was applied to human oral biopsies and revealed a proteomic signature for squamous cell carcinomas (129).
Esophagus. Several prognostic markers could be identified in Barrett's adenocarcinoma (103).

Stomach. IMS was able to discern between the gastric cancer and the normal gastric mucosa (79). Furthermore, protein profiles from early stage gastric cancer were significantly different from advanced stage gastric tumors (79). Also, specific signals for poorly differentiated gastric cancer were found (16). Choi et al (109) identified proteins as negative regulators for lymph node metastasis in gastric adenocarcinoma. A seven-protein signature was associated with unfavorable overall survival independent of major clinical covariates as demonstrated by MALDI IMS on frozen tissues (78).

Colon. Thomas et al (130) applied IMS technique to detect lipids in human colorectal liver metastasis biopsies. With the help of a tissue based proteomic approach, a large panel of proteins that are associated with regional lymph node metastasis was identified (13). The penetration and distribution of platinum-based metallodrugs was demonstrated in metastatic tissue of colon cancer by IMS (113).

Pancreas. Djidja et al (81) identified a glucose-regulated protein as a biomarker within pancreatic tumor tissue sections. Grüner et al (77) detected several discriminative $\mathrm{m} / \mathrm{z}$ species that could distinguish between intraepithelial neoplasia, intraductal papillary mucinous neoplasm and normal pancreatic tissue in genetically engineered mouse models. Moreover, metastatic tissue from breast cancer could be discerned from pancreatic cancer with an overall accuracy of $83.38 \%$, a sensitivity of $85.95 \%$ and a specificity of $76.96 \%$ resulting in a more accurate result than immunohistochemistry even when several antibodies are applied (83).

Investigation of large tissue sections of duodenal mucosa, normal pancreatic tissue and pancreatic carcinoma by MALDI IMS could clearly discern the various tissue compartments (Fig. 5). This method allows 'painting' of the different tissues 
a

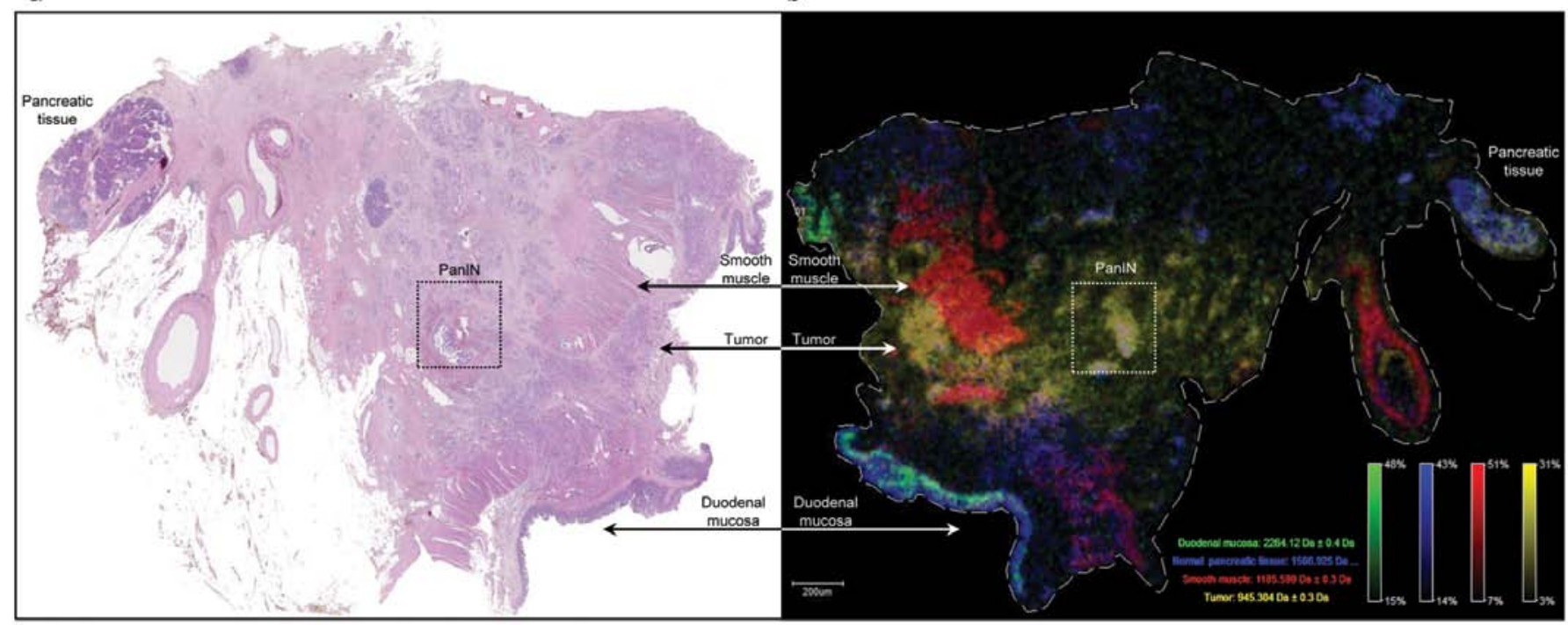

Figure 5. Image correlation between MALDI IMS analysis and histochemistry of one pancreatic tumor tissue sample. (a) H\&E stained section. (b) Shows MALDI image distribution of peptide species specifically localized in the tumor $(\mathrm{m} / \mathrm{z}$ 945), the duodenal epithelium (m/z 2264$)$, normal pancreatic tissue (m/z 1506) and smooth muscle (m/z 1185). Pancreatic intraepithelial neoplasia (PanIN) is highlighted by a square.

by tissue specific peptide signals in tumor cells (m/z 945), duodenal epithelium (m/z 2264), normal pancreatic tissue (m/z 1506) and smooth muscle (m/z 1185).

Liver. Le Faouder et al (75) were able to distinguish hepatocellular carcinoma from cirrhosis by IMS.

Lung. Rahman et al (131) and Yanagisawa et al (76) reported proteomic patterns specific for normal alveolar and bronchial tissues, pre-invasive lesions and invasive lung cancer. Analysis of microarrays of biopsies from adenocarcinoma and squamous cell carcinoma was performed by Groseclose et al (67) and could clearly discern both tumor types without immunohistochemistry. Besides the proteomic profile, lung cancer could be subclassified also by lipid analysis (132). Proteomic strategies in lung cancer diagnostics in tissue, blood and serum are described elsewhere in detail (133). Notably, EGF-receptor antagonists as target drugs in lung cancer were characterized in lung cancer tissue (111).

Lymphoma.IMS was applied to Hodgkin's lymphoma and could result in pinpointing differentially expressed molecules, which might represent potential biomarkers. Schwamborn et al (134) could distinguish between classical Hodgkin lymphoma and lymphadenitis.

Skin. Skin malignancies, especially melanoma, are another field where MALDI IMS has been applied successfully. Hardesty et al (105) found peptides that discriminate prognostic subgroups in melanoma patients. Additionally, this group identified signatures associated with favorable and poor survival. IMS has also been utilized to differentiate Spitz naevus and melanoma, which is important due to the completely different therapeutic consequences of both entities (135). Sugihara et al (112) introduced IMS to provide new information on one of the drugs (vemurafenib) currently used in the treatment of malignant melanoma.
Thyroid. MALDI IMS studies have rarely been performed on thyroid cancer tissue. IMS techniques have been used to discriminate thyroid cancer specific peptides from normal thyroid tissue (136). The authors found a thyroid cancer specific protein, however, only five patients were included in the study. Other investigators (14) identified not only a specific proteomic pattern to discriminate non-metastatic from metastatic thyroid cancers but showed also a functional relationship between these proteins and a specific pathway. Pagni et al (66) were able to distinguish between different thyroid lesions applying IMS to fine needle aspiration smears. In the present review, unsupervised statistical analysis and principal component analysis were used to cluster proteomic spectra between papillary thyroid carcinoma, Hürthle cell adenoma, medullary thyroid carcinoma and hyperplastic nodules. Different proteomic signatures were obtained between the histological types with a receiver operating characteristic (ROC) analysis showing an area under the curve $>0.8$, and a Student's t-test $\mathrm{P}$-value $<0.05$. For example, three different proteins detected at 4965, 6278 and $6651 \mathrm{~m} / \mathrm{z}$ were downregulated in the Hürthle cell adenoma, medullary thyroid carcinoma and papillary thyroid carcinoma patients, when compared to patients with hyperplastic nodules. Nevertheless, by comparing the proteomic profiles obtained from the Hürthle cell adenoma patients with the medullary thyroid carcinoma patients, proteins at 7263,8294 and $8310 \mathrm{~m} / \mathrm{z}$ were differentially expressed between the two entities. With these results, investigators highlighted a potential role of MALDI IMS as a supporting tool to discriminate malignant from benign thyroid lesions as well as between different types of thyroid lesions.

\section{Urogenital tract}

Kidney. Oppenheimer et al (44) studied tumor margins of renal cell carcinoma by IMS. Junker et al (137) analyzed stage-related protein alterations in kidney cancer using 
MALDI TOF MS/MS but not IMS. Chinello et al (138) were able to discriminate patients with renal cell carcinoma from normal controls by MALDI TOF technique applied to serum. IMS has been used to identify and map specific peptides that accurately distinguished malignant from normal renal tissue (72). Axt et al (139) identified spectra from both Wilms' tumor blastema and stroma that independently classified specimens according to race with an accuracy of $>80 \%$.

Bladder. Oezdemir et al (106) reported improvement of grading of non-invasive papillary urothelial neoplasia applying IMS. A recent report utilized IMS for the analysis of a bladder cancer tissue microarray to evaluate prognostically relevant molecules (140). From the analysis of 697 patients, numerous $\mathrm{m} / \mathrm{z}$ signals were found statistically associated with one or several phenotypes including decrease (12 signals) or increase (6 signals) of cell proliferation, papillary (3 signals) or solid (5 signals) growth pattern, and tumor aggressiveness based on stage, grade and nodal status (30 signals).

Ovary. Lemaire et al (102) not only discriminated between benign and malignant ovarian tumors, but identified a new candidate protein biomarker only present in ovarian carcinoma.

Specific proteins in tumor interface zones associated with ovarian serous cancer tissues, were described by Kang et al (98). Liu et al (141) demonstrated that sulfatides are more abundant in ovarian cancer than control tissues.

By analysis of tryptic digests of the FFPE tissue microarray cores by LC-MS/MS, various $\mathrm{m} / \mathrm{z}$ species observed in MALDI IMS experiments on ovarian cancer could be correctly identified (142). Drug distribution of platinum-based drugs was shown in peritoneal carcinomatosis of ovarian cancer (113).

Prostate. Studies of prostate cancer have utilized IMS to aid diagnosis and for the discovery of proteins relevant to the underlying biology $(41,82,143)$. The first clinical study of human prostate cancer by IMS was performed by Schwambor et al (41).

A specific fragment of mitogen activated protein kinase could discriminate cancer from normal prostatic tissue (143). Furthermore, a marker for early recurrence of prostate cancer has been identified by Steurer et al (82).

Sarcomas. One report utilized IMS for the classification of myxoid sarcomas. Willems et al (40) could discriminate myxofibrosarcoma and myxoid liposarcoma that may share a similar histology. Furthermore, intratumoral heterogeneity was demonstrated in myxofibrosarcomas.

\section{Summary}

MALDI IMS is a versatile technique which had been applied to various organisms including plants, animals and human tissue. In human tissue and cells, tumor-associated alterations were studied in various entities. MALDI IMS may improve exact determination of tumor margins, tumor typing, grading and prognosis and could have therapeutic implications.

Diagnostic procedures in pathology are based on histology, histochemistry, immunohistochemistry and molecular pathology and will include proteomic techniques like MALDI IMS to improve diagnostic accuracy.

\section{Perspectives}

MALDI IMS will extend or replace histochemical techniques such as periodic acid-Schiff- and Prussian blue-reaction as well as methods that highlight connective tissue compounds as Masson's trichrome reaction. Additionally, we foresee that immunohistochemical methods will be at least partly replaced by IMS. This is of great importance, especially if molecular testing is required for diagnostics and only small tissue biopsies are available for such tests. In this regard, MALDI IMS requires only one tissue section for the analysis, thus adequate remaining tissue is available for additional molecular testing. In this scenario, elaborate molecular testing of DNA and RNA alterations will be performed either by next generation sequencing or by mass spectrometric techniques. Applications of IMS in the clinic are growing as this technology has proved its feasibility and versatility. The implementation of biocomputational tools combined with IMS will allow biostatistical evaluation for determination of molecular signals able to type or grade tumors and will provide information about prognosis. Furthermore, drug distribution in different tissue types and cellular components may be monitored by IMS. To ensure similar sample preparation and processing, robust standard operating procedures need to be developed for the application of IMS in routine histopathology. Quality control will be achieved by interlaboratory validation as well as by sharing large databases of MALDI signatures of tumors or other diseases.

\section{References}

1. Patel R: MALDI-TOF mass spectrometry: transformative proteomics for clinical microbiology. Clin Chem 59: 340-342, 2013.

2. Clark AE, Kaleta EJ, Arora A and Wolk DM: Matrix-assisted laser desorption ionization-time of flight mass spectrometry: a fundamental shift in the routine practice of clinical microbiology. Clin Microbiol Rev 26: 547-603, 2013.

3. Moore JL, Caprioli RM and Skaar EP: Advanced mass spectrometry technologies for the study of microbial pathogenesis. Curr Opin Microbiol 19C: 45-51, 2014.

4. Kueger S, Steinhauser D, Willmitzer L and Giavalisco P: Highresolution plant metabolomics: from mass spectral features to metabolites and from whole-cell analysis to subcellular metabolite distributions. Plant J 70: 39-50, 2012.

5. Schoenian I, Spiteller M, Ghaste M, Wirth R, Herz H and Spiteller D: Chemical basis of the synergism and antagonism in microbial communities in the nests of leaf-cutting ants. Proc Natl Acad Sci USA 108: 1955-1960, 2011.

6. Chaurand P, Cornett DS, Angel PM and Caprioli RM: From whole-body sections down to cellular level, multiscale imaging of phospholipids by MALDI mass spectrometry. Mol Cell Proteomics 10: O110.004259, 2011.

7. Trim PJ, Henson CM, Avery JL, et al: Matrix-assisted laser desorption/ionization-ion mobility separation-mass spectrometry imaging of vinblastine in whole body tissue sections. Anal Chem 80: 8628-8634, 2008.

8. Reyzer ML, Chaurand P, Angel PM and Caprioli RM: Direct molecular analysis of whole-body animal tissue sections by MALDI imaging mass spectrometry. Methods Mol Biol 656: 285-301, 2010.

9. Remmerbach TW, Maurer K, Janke S, et al: Oral brush biopsy analysis by matrix assisted laser desorption/ionisation-time of flight mass spectrometry profiling: a pilot study. Oral Oncol 47: 278-281, 2011.

10. Schwamborn K, Krieg RC, Uhlig S, Ikenberg H and Wellmann A: MALDI imaging as a specific diagnostic tool for routine cervical cytology specimens. Int J Mol Med 27: 417-421, 2011. 
11. Kriegsmann M, Seeley EH, Schwarting A, et al: MALDI MS imaging as a powerful tool for investigating synovial tissue. Scand J Rheumatol 41: 305-309, 2012.

12. Seeley EH and Caprioli RM: MALDI imaging mass spectrometry of human tissue: method challenges and clinical perspectives. Trends Biotechnol 29: 136-143, 2011.

13. Meding S, Nitsche U, Balluff B, et al: Tumor classification of six common cancer types based on proteomic profiling by MALDI imaging. J Proteome Res 11: 1996-2003, 2012.

14. Nipp M, Elsner M, Balluff B, et al: S100-A10, thioredoxin, and S100-A6 as biomarkers of papillary thyroid carcinoma with lymph node metastasis identified by MALDI imaging. J Mol Med 90: 163-174, 2012.

15. Steurer S, Seddiqi AS, Singer JM, et al: MALDI imaging on tissue microarrays identifies molecular features associated with renal cell cancer phenotype. Anticancer Res 34: 2255-2261, 2014

16. Morita Y, Ikegami K, Goto-Inoue N, et al: Imaging mass spectrometry of gastric carcinoma in formalin-fixed paraffinembedded tissue microarray. Cancer Sci 101: 267-273, 2010.

17. Gode D and Volmer DA: Lipid imaging by mass spectrometry - a review. Analyst 138: 1289-1315, 2013.

18. Horn PJ and Chapman KD: Lipidomics in situ: insights into plant lipid metabolism from high resolution spatial maps of metabolites. Prog Lipid Res 54: 32-52, 2014.

19. Sparvero LJ, Amoscato AA, Dixon CE, et al: Mapping of phospholipids by MALDI imaging (MALDI-MSI): realities and expectations. Chem Phys Lipids 165: 545-562, 2012.

20. Harvey DJ: Analysis of carbohydrates and glycoconjugates by matrix-assisted laser desorption/ionization mass spectrometry: An update for 2009-2010. Mass Spectrom Rev: May 26, 2014 doi: 10.1002/mas.21411 (Epub ahead of print).

21. Reyzer ML, Hsieh Y, Ng K, Korfmacher WA and Caprioli RM: Direct analysis of drug candidates in tissue by matrix-assisted laser desorption/ionization mass spectrometry. J Mass Spectrom 38: 1081-1092, 2003.

22. Norris JL and Caprioli RM: Analysis of tissue specimens by matrix-assisted laser desorption/ionization imaging mass spectrometry in biological and clinical research. Chem Rev 113 2309-2342, 2013.

23. Groseclose MR and Castellino S: A mimetic tissue model for the quantification of drug distributions by MALDI imaging mass spectrometry. Anal Chem 85: 10099-10106, 2013.

24. Honisch C, Chen Y, Mortimer C, et al: Automated comparative sequence analysis by base-specific cleavage and mass spectrometry for nucleic acid-based microbial typing. Proc Natl Acad Sci USA 104: 10649-10654, 2007.

25. Okamoto I, Sakai K, Morita S, et al: Multiplex genomic profiling of non-small cell lung cancers from the LETS phase III trial of first-line S-1/carboplatin versus paclitaxel/carboplatin: results of a West Japan Oncology Group study. Oncotarget 5: 2293-2304, 2014.

26. Castellino S, Groseclose MR and Wagner D: MALDI imaging mass spectrometry: bridging biology and chemistry in drug development. Bioanalysis 3: 2427-2441, 2011

27. Rompp A, Guenther S, Takats Z and Spengler B: Mass spectrometry imaging with high resolution in mass and space (HR(2) MSI) for reliable investigation of drug compound distributions on the cellular level. Anal Bioanal Chem 401: 65-73, 2011.

28. Caprioli RM, Farmer TB and Gile J: Molecular imaging of biological samples: localization of peptides and proteins using MALDI-TOF MS. Anal Chem 69: 4751-4760, 1997.

29. Schone $C$, Hofler $H$ and Walch A: MALDI imaging mass spectrometry in cancer research: combining proteomic profiling and histological evaluation. Clin Biochem 46: 539-545, 2013.

30. Gessel MM, Norris JL and Caprioli RM: MALDI imaging mass spectrometry: spatial molecular analysis to enable a new age of discovery. J Proteomics 107: 71-82, 2014.

31. Thomas A, Lenglet S, Chaurand P, et al: Mass spectrometry for the evaluation of cardiovascular diseases based on proteomics and lipidomics. Thromb Haemost 106: 20-33, 2011.

32. McClure RA, Chumbley CW, Reyzer ML, et al: Identification of promethazine as an amyloid-binding molecule using a fluorescence high-throughput assay and MALDI imaging mass spectrometry. Neuroimage Clin 2: 620-629, 2013.

33. Kriegsmann M, Casadonte R, Randau T, et al: MALDI imaging of predictive ferritin, fibrinogen and proteases in haemophilic arthropathy. Haemophilia 20: 446-453, 2014.

34. Seeley EH and Caprioli RM: Molecular imaging of proteins in tissues by mass spectrometry. Proc Natl Acad Sci USA 105 18126-18131, 2008.
35. Seeley EH, Washington MK, Caprioli RM and M'Koma AE: Proteomic patterns of colonic mucosal tissues delineate Crohn's colitis and ulcerative colitis. Proteomics Clin Appl 7: 541-549, 2013.

36. Lalowski M, Magni F, Mainini V, et al: Imaging mass spectrometry: a new tool for kidney disease investigations. Nephrol Dial Transplant 28: 1648-1656, 2013.

37. Mainini V, Pagni F, Ferrario F, et al: MALDI imaging mass spectrometry in glomerulonephritis: feasibility study. Histopathology 64: 901-906, 2014

38. Xu BJ, Shyr Y, Liang X, et al: Proteomic patterns and prediction of glomerulosclerosis and its mechanisms. J Am Soc Nephrol 16: 2967-2975, 2005

39. Lagarrigue M, Becker M, Lavigne R, et al: Revisiting rat spermatogenesis with MALDI imaging at 20-microm resolution. Mol Cell Proteomic 10: M110.005991, 2011.

40. Willems SM, van Remoortere A, van Zeijl R, Deelder AM, McDonnell LA and Hogendoorn PC: Imaging mass spectrometry of myxoid sarcomas identifies proteins and lipids specific to tumour type and grade, and reveals biochemical intratumour heterogeneity. J Pathol 222: 400-409, 2010.

41. Schwamborn K, Krieg RC, Reska M, Jakse G, Knuechel R and Wellmann A: Identifying prostate carcinoma by MALDIImaging. Int J Mol Med 20: 155-159, 2007.

42. Rodrigo MA, Zitka O, Krizkova S, Moulick A, Adam V and Kizek R: MALDI-TOF MS as evolving cancer diagnostic tool: a review. J Pharm Biomed Anal 95: 245-255, 2014.

43. Rahman SM, Gonzalez AL, Li M, et al: Lung cancer diagnosis from proteomic analysis of preinvasive lesions. Cancer Res 71: 3009-3017, 2011

44. Oppenheimer SR, Mi D, Sanders ME and Caprioli RM: Molecular analysis of tumor margins by MALDI mass spectrometry in renal carcinoma. J Proteome Res 9: 2182-2190, 2010.

45. Jones EE, Powers TW, Neely BA, et al: MALDI imaging mass spectrometry profiling of proteins and lipids in clear cell renal cell carcinoma. Proteomics 14: 924-935, 2014.

46. Angel PM and Caprioli RM: Matrix-assisted laser desorption ionization imaging mass spectrometry: in situ molecular mapping. Biochemistry 52: 3818-3828, 2013.

47. Boggio KJ, Obasuyi E, Sugino K, Nelson SB, Agar NY and Agar JN: Recent advances in single-cell MALDI mass spectrometry imaging and potential clinical impact. Expert Rev Proteomics 8: 591-604, 2011

48. Eriksson C, Masaki N, Yao I, Hayasaka T and Setou M: MALDI imaging mass spectrometry-A mini review of methods and recent developments. Mass Spectrom 2: S0022, 2013.

49. Dreisewerd K: Recent methodological advances in MALDI mass spectrometry. Anal Bioanal Chem 406: 2261-2278, 2014.

50. Fujimura Y and Miura D: MALDI mass spectrometry imaging for visualizing in situ metabolism of endogenous metabolites and dietary phytochemicals. Metabolites 4: 319-346, 2014.

51. Gorzolka K and Walch A: MALDI mass spectrometry imaging of formalin-fixed paraffin-embedded tissues in clinical research. Histol Histopathol 29: 1365-1376, 2014

52. Schwamborn K and Caprioli RM: Molecular imaging by mass spectrometry: looking beyond classical histology. Nat Rev Cancer 10: 639-646, 2010.

53. Chaurand P: Imaging mass spectrometry of thin tissue sections: a decade of collective efforts. J Proteomics 75: 4883-4892, 2012.

54. Rompp A and Spengler B: Mass spectrometry imaging with high resolution in mass and space. Histochem Cell Biol 139: 759-783, 2013.

55. Goodwin RJ: Sample preparation for mass spectrometry imaging: small mistakes can lead to big consequences. J Proteomics 75 4893-4911, 2012.

56. Kaletas BK, van der Wiel IM, Stauber J, et al: Sample preparation issues for tissue imaging by imaging MS. Proteomics 9: 2622-2633, 2009.

57. Stoeckli M, Chaurand P, Hallahan DE and Caprioli RM: Imaging mass spectrometry: a new technology for the analysis of protein expression in mammalian tissues. Nat Med 7: 493-496, 2001.

58. Cornett DS, Mobley JA, Dias EC, et al: A novel histologydirected strategy for MALDI-MS tissue profiling that improves throughput and cellular specificity in human breast cancer. Mol Cell Proteomics 5: 1975-1983, 2006.

59. Seeley EH, Schwamborn K and Caprioli RM: Imaging of intact tissue sections: moving beyond the microscope. J Biol Chem 286 25459-25466, 2011.

60. Zavalin A, Yang J and Caprioli R: Laser beam filtration for high spatial resolution MALDI imaging mass spectrometry. J Am Soc Mass Spectrom 24: 1153-1156, 2013. 
61. Caprioli RM: Imaging mass spectrometry: molecular microscopy for enabling a new age of discovery. Proteomics 14: 807-809, 2014.

62. Norris JL, Cornett DS, Mobley JA, et al: Processing MALDI Mass Spectra to improve mass spectral direct tissue analysis. Int J Mass Spectrom 260: 212-221, 2007.

63. Djidja MC, Claude E, Snel MF, et al: Novel molecular tumour classification using MALDI-mass spectrometry imaging of tissue micro-array. Anal Bioanal Chem 397: 587-601, 2010.

64. Andersson M, Groseclose MR, Deutch AY and Caprioli RM: Imaging mass spectrometry of proteins and peptides: $3 \mathrm{D}$ volume reconstruction. Nat Methods 5: 101-108, 2008.

65. Crecelius AC, Cornett DS, Caprioli RM, Williams B, Dawant BM and Bodenheimer B: Three-dimensional visualization of protein expression in mouse brain structures using imaging mass spectrometry. J Am Soc Mass Spectrom 16: 1093-1099, 2005.

66. Pagni F, Mainini V, Garancini M, et al: Proteomics for the diagnosis of thyroid lesions: preliminary report. Cytopathology: Jul 20, 2014. doi: 10.1111/cyt.12166 (Epub ahead of print)

67. Groseclose MR, Massion PP, Chaurand P and Caprioli RM: High-throughput proteomic analysis of formalin-fixed paraffinembedded tissue microarrays using MALDI imaging mass spectrometry. Proteomics 8: 3715-3724, 2008.

68. Gancberg D, Jarvinen T, di Leo A, et al: Evaluation of HER-2/ NEU protein expression in breast cancer by immunohistochemistry: an interlaboratory study assessing the reproducibility of HER-2/NEU testing. Breast Cancer Res Treat 74: 113-120, 2002

69. Thaysen-Andersen M, Wilkinson BL, Payne RJ and Packer NH: Site-specific characterisation of densely O-glycosylated mucintype peptides using electron transfer dissociation ESI-MS/MS Electrophoresis 32: 3536-3545, 2011.

70. Ronci M, Sharma S, Chataway T, et al: MALDI-MS-imaging of whole human lens capsule. J Proteome Res 10: 3522-3529, 2011.

71. Bona A, Papai Z, Maasz G, et al: Mass spectrometric identification of ancient proteins as potential molecular biomarkers for a 2000-year-old osteogenic sarcoma. PLoS One 9: e87215, 2014.

72. Morgan TM, Seeley EH, Fadare O, Caprioli RM and Clark PE: Imaging the clear cell renal cell carcinoma proteome. J Urol 189: 1097-1103, 2013

73. Dekker TJ, Balluff BD, Jones EA, et al: Multicenter Matrixassisted laser desorption/ionization mass spectrometry imaging (MALDI MSI) identifies proteomic differences in breast-cancerassociated stroma. J Proteome Res: May 2, 2014. (Epub ahead of print)

74. Rauser S, Marquardt C, Balluff B, et al: Classification of HER2 receptor status in breast cancer tissues by MALDI imaging mass spectrometry. J Proteome Res 9: 1854-1863, 2010.

75. Le Faouder J, Laouirem S, Chapelle M, et al: Imaging mass spectrometry provides fingerprints for distinguishing hepatocellular carcinoma from cirrhosis. J Proteome Res 10: 3755-3765, 2011.

76. Yanagisawa K, Shyr Y,Xu BJ, et al: Proteomic patterns of tumour subsets in non-small-cell lung cancer. Lancet 362: 433-439, 2003.

77. Gruner BM, Hahne H, Mazur PK, et al: MALDI imaging mass spectrometry for in situ proteomic analysis of preneoplastic lesions in pancreatic cancer. PLoS One 7: e39424, 2012.

78. Balluff B, Rauser S, Meding S, et al: MALDI imaging identifies prognostic seven-protein signature of novel tissue markers in intestinal-type gastric cancer. Am J Pathol 179: 2720-2729, 2011.

79. Kim HK, Reyzer ML, Choi IJ, et al: Gastric cancer-specific protein profile identified using endoscopic biopsy samples via MALDI mass spectrometry. J Proteome Res 9: 4123-4130, 2010.

80. Casadonte R and Caprioli RM: Proteomic analysis of formalinfixed paraffin-embedded tissue by MALDI imaging mass spectrometry. Nat Protoc 6: 1695-1709, 2011

81. Djidja MC, Chang J, Hadjiprocopis A, et al: Identification of hypoxia-regulated proteins using MALDI-mass spectrometry imaging combined with quantitative proteomics. J Proteome Res 13: 2297-2313, 2014

82. Steurer S, Borkowski C, Odinga S, et al: MALDI mass spectrometric imaging based identification of clinically relevant signals in prostate cancer using large-scale tissue microarrays. Int J Cancer 133: 920-928, 2013.

83. Casadonte R, Kriegsmann M, Zweynert F, et al: Imaging mass spectrometry to discriminate breast from pancreatic cancer metastasis in formalin-fixed paraffin-embedded tissues. Proteomics 14: 956-964, 2014

84. Ikeda K, Monden T, Kanoh T, et al: Extraction and analysis of diagnostically useful proteins from formalin-fixed, paraffinembedded tissue sections. J Histochem Cytochem 46: 397-403, 1998.
85. Becker KF, Schott C, Hipp S, et al: Quantitative protein analysis from formalin-fixed tissues: implications for translational clinical research and nanoscale molecular diagnosis. J Pathol 211: 370-378, 2007

86. Chung JY, Lee SJ, Kris Y, Braunschweig T, Traicoff JL and Hewitt SM: A well-based reverse-phase protein array applicable to extracts from formalin-fixed paraffin-embedded tissue. Proteomics Clin Appl 2: 1539-1547, 2008.

87. Nirmalan NJ, Harnden P, Selby PJ and Banks RE: Development and validation of a novel protein extraction methodology for quantitation of protein expression in formalin-fixed paraffinembedded tissues using western blotting. J Pathol 217: 497-506, 2009.

88. Crockett DK, Lin Z, Vaughn CP, Lim MS and ElenitobaJohnson KS: Identification of proteins from formalin-fixed paraffin-embedded cells by LC-MS/MS. Lab Invest 85 : 1405-1415, 2005.

89. Hood BL, Darfler MM, Guiel TG, et al: Proteomic analysis of formalin-fixed prostate cancer tissue. Mol Cell Proteomics 4: $1741-1753,2005$.

90. Palmer-Toy DE, Krastins B, Sarracino DA, Nadol JB Jr and Merchant SN: Efficient method for the proteomic analysis of fixed and embedded tissues. J Proteome Res 4: 2404-2411, 2005.

91. Becker KF, Berg D, Malinowsky K, et al: Update on protein analysis of fixed tissues. Pathologe 31 (Suppl 2): 263-267, 2010.

92. Shi SR, Liu C, Balgley BM, Lee C and Taylor CR: Protein extraction from formalin-fixed, paraffin-embedded tissue sections: quality evaluation by mass spectrometry. J Histochem Cytochem 54: 739-743, 2006.

93. McDonnell LA, Walch A, Stoeckli M and Corthals GL: MSiMass list: a public database of identifications for protein MALDI MS imaging. J Proteome Res 13: 1138-1142, 2014

94. Maier SK, Hahne H, Gholami AM, et al: Comprehensive identification of proteins from MALDI imaging. Mol Cell Proteomics 12: 2901-2910, 2013.

95. Deininger SO, Ebert MP, Futterer A, Gerhard M and Rocken C: MALDI imaging combined with hierarchical clustering as a new tool for the interpretation of complex human cancers. J Proteome Res 7: 5230-5236, 2008

96. Caprioli RM: Deciphering protein molecular signatures in cancer tissues to aid in diagnosis, prognosis, and therapy. Cancer Res 65: 10642-10645, 2005.

97. Chaurand P, Sanders ME, Jensen RA and Caprioli RM Proteomics in diagnostic pathology: profiling and imaging proteins directly in tissue sections. Am J Pathol 165: 1057-1068, 2004.

98. Kang S, Shim HS, Lee JS, et al: Molecular proteomics imaging of tumor interfaces by mass spectrometry. J Proteome Res 9: $1157-1164,2010$

99. Han EC, Lee YS, Liao WS, Liu YC, Liao HY and Jeng LB: Direct tissue analysis by MALDI-TOF mass spectrometry in human hepatocellular carcinoma. Clin Chim Acta 412: 230-239, 2011

100. Eberlin LS, Norton I, Orringer D, et al: Ambient mass spectrometry for the intraoperative molecular diagnosis of human brain tumors. Proc Natl Acad Sci USA 110: 1611-1616, 2013.

101. Schwartz SA, Weil RJ, Thompson RC, et al: Proteomic-based prognosis of brain tumor patients using direct-tissue matrixassisted laser desorption ionization mass spectrometry. Cancer Res 65: 7674-7681, 2005.

102. Lemaire R, Menguellet SA, Stauber J, et al: Specific MALDI imaging and profiling for biomarker hunting and validation: fragment of the 11S proteasome activator complex, Reg alpha fragment, is a new potential ovary cancer biomarker. J Proteome Res 6: 4127-4134, 2007.

103. Elsner M, Rauser S, Maier S, et al: MALDI imaging mass spectrometry reveals COX7A2, TAGLN2 and S100-A10 as novel prognostic markers in Barrett's adenocarcinoma. J Proteomics 75: 4693-4704, 2012.

104. Flatley B, Malone P and Cramer R: MALDI mass spectrometry in prostate cancer biomarker discovery. Biochim Biophys Acta 1844: 940-949, 2014.

105. Hardesty WM, Kelley MC, Mi D, Low RL and Caprioli RM: Protein signatures for survival and recurrence in metastatic melanoma. J Proteomics 74: 1002-1014, 2011.

106. Oezdemir RF, Gaisa NT, Lindemann-Docter K, et al: Proteomic tissue profiling for the improvement of grading of noninvasive papillary urothelial neoplasia. Clin Biochem 45: 7-11, 2012.

107. Chaurand P, Schwartz SA, Billheimer D, Xu BJ, Crecelius A and Caprioli RM: Integrating histology and imaging mass spectrometry. Anal Chem 76: 1145-1155, 2004. 
108. Schwartz SA, Weil RJ, Johnson MD, Toms SA and Caprioli RM: Protein profiling in brain tumors using mass spectrometry: feasibility of a new technique for the analysis of protein expression. Clin Cancer Res 10: 981-987, 2004.

109. Choi JH, Shin NR, Moon HJ, et al: Identification of S100A8 and S100A9 as negative regulators for lymph node metastasis of gastric adenocarcinoma. Histol Histopathol 27: 1439-1448, 2012.

110. Reyzer ML, Caldwell RL, Dugger TC, et al: Early changes in protein expression detected by mass spectrometry predict tumor response to molecular therapeutics. Cancer Res 64: 9093-9100, 2004.

111. Vegvari A, Fehniger TE, Rezeli M, et al: Experimental models to study drug distributions in tissue using MALDI mass spectrometry imaging. J Proteome Res 12: 5626-5633, 2013.

112. Sugihara Y, Vegvari A, Welinder C, et al: A new look at drugs targeting malignant melanoma - an application for mass spectrometry imaging. Proteomics 14: 1963-1970, 2014.

113. Bianga J, Bouslimani A, Bec N, et al: Complementarity of MALDI and LA ICP mass spectrometry for platinum anticancer imaging in human tumor. Metallomics 6: 1382-1386, 2014.

114. Liu X, Ide JL, Norton I, et al: Molecular imaging of drug transit through the blood-brain barrier with MALDI mass spectrometry imaging. Sci Rep 3: 2859, 2013.

115. Buck A and Walch A: In situ drug and metabolite analyzes in biological and clinical research by MALDI MS imaging. Bioanalysis 6: 1241-1253, 2014.

116. Jirasko R,Holcapek M,Kunes M and Svatos A: Distribution study of atorvastatin and its metabolites in rat tissues using combined information from UHPLC/MS and MALDI-Orbitrap-MS imaging. Anal Bioanal Chem 406: 4601-4610, 2014.

117. Huber K, Aichler M, Sun N, et al: A rapid ex vivo tissue model for optimising drug detection and ionisation in MALDI imaging studies. Histochem Cell Biol 142: 361-371, 2014.

118. Yasunaga M, Furuta M, Ogata K, et al: The significance of microscopic mass spectrometry with high resolution in the visualisation of drug distribution. Sci Rep 3: 3050, 2013.

119. Salphati L, Shahidi-Latham S, Quiason C, et al: Distribution of the phosphatidylinositol 3-kinase inhibitors Pictilisib (GDC0941) and GNE-317 in U87 and GS2 intracranial glioblastoma models-assessment by matrix-assisted laser desorption ionization imaging. Drug Metab Dispos 42: 1110-1116, 2014.

120.Zecchi R, Trevisani M, Pittelli M, et al: Impact of drug administration route on drug delivery and distribution into the lung: an imaging mass spectrometry approach. Eur J Mass Spectrom 19: 475-482, 2013.

121. Bouamrani A, Ternier J, Ratel D, et al: Direct-tissue SELDI-TOF mass spectrometry analysis: a new application for clinical proteomics. Clin Chem 52: 2103-2106, 2006.

122. Agar NY, Malcolm JG, Mohan V, et al: Imaging of meningioma progression by matrix-assisted laser desorption ionization timeof-flight mass spectrometry. Anal Chem 82: 2621-2625, 2010.

123. Ronci M, Bonanno E, Colantoni A, et al: Protein unlocking procedures of formalin-fixed paraffin-embedded tissues: application to MALDI-TOF imaging MS investigations. Proteomics 8: 3702-3714, 2008

124. Qin XJ and Ling BX: Proteomic studies in breast cancer (Review). Oncol Lett 3: 735-743, 2012.

125. Seeley EH and Caprioli RM: Imaging mass spectrometry: towards clinical diagnostics. Proteomics Clin Appl 2: 1435-1443, 2008

126. Walch A, Rauser S, Deininger SO and Hofler H: MALDI imaging mass spectrometry for direct tissue analysis: a new frontier for molecular histology. Histochem Cell Biol 130: 421-434, 2008.
127. Amstalden van Hove ER, Blackwell TR, Klinkert I, Eijkel GB, Heeren RM and Glunde K: Multimodal mass spectrometric imaging of small molecules reveals distinct spatio-molecular signatures in differentially metastatic breast tumor models. Cancer Res 70: 9012-9021, 2010.

128. Chughtai K, Jiang L, Greenwood TR, Glunde K and Heeren RM: Mass spectrometry images acylcarnitines, phosphatidylcholines, and sphingomyelin in MDA-MB-231 breast tumor models. J Lipid Res 54: 333-344, 2013.

129. Patel SA, Barnes A, Loftus N, et al: Imaging mass spectrometry using chemical inkjet printing reveals differential protein expression in human oral squamous cell carcinoma. Analyst 134: 301-307, 2009

130. Thomas A, Patterson NH, Marcinkiewicz MM, Lazaris A, Metrakos P and Chaurand P: Histology-driven data mining of lipid signatures from multiple imaging mass spectrometry analyses: application to human colorectal cancer liver metastasis biopsies. Anal Chem 85: 2860-2866, 2013.

131. Rahman SM, Shyr Y, Yildiz PB, et al: Proteomic patterns of preinvasive bronchial lesions. Am J Respir Crit Care Med 172: 1556-1562, 2005.

132. Lee GK, Lee HS, Park YS, et al: Lipid MALDI profile classifies non-small cell lung cancers according to the histologic type. Lung Cancer 76: 197-203, 2012.

133. Hassanein M, Rahman JS, Chaurand P and Massion PP: Advances in proteomic strategies toward the early detection of lung cancer. Proc Am Thorac Soc 8: 183-188, 2011.

134. Schwamborn K, Krieg RC, Jirak P, et al: Application of MALDI imaging for the diagnosis of classical Hodgkin lymphoma. J Cancer Res Clin Oncol 136: 1651-1655, 2010.

135. Lazova R, Seeley EH, Keenan M, Gueorguieva R and Caprioli RM: Imaging mass spectrometry - a new and promising method to differentiate Spitz nevi from Spitzoid malignant melanomas. Am J Dermatopathol 34: 82-90, 2012.

136. Min KW, Bang JY, Kim KP, et al: Imaging mass spectrometry in papillary thyroid carcinoma for the identification and validation of biomarker proteins. J Korean Med Sci 29: 934-940, 2014.

137. Junker H, Venz S, Zimmermann U, Thiele A, Scharf C and Walther R: Stage-related alterations in renal cell carcinomacomprehensive quantitative analysis by 2D-DIGE and protein network analysis. PLoS One 6: e21867, 2011.

138. Chinello C, Gianazza E, Zoppis I, et al: Serum biomarkers of renal cell carcinoma assessed using a protein profiling approach based on ClinProt technique. Urology 75: 842-847, 2010.

139. Axt J, Murphy AJ, Seeley EH, et al: Race disparities in Wilms tumor incidence and biology. J Surg Res 170: 112-119, 2011.

140. Steurer S, Singer JM, Rink M, et al: MALDI imaging-based identification of prognostically relevant signals in bladder cancer using large-scale tissue microarrays. Urol Oncol: Aug 14, 2014. doi: 10.1016/j.urolonc.2014.06.007 (Epub ahead of print)

141. Liu Y, Chen Y, Momin A, et al: Elevation of sulfatides in ovarian cancer: an integrated transcriptomic and lipidomic analysis including tissue-imaging mass spectrometry. Mol Cancer 9: 186, 2010.

142. Meding S, Martin K, Gustafsson OJ, et al: Tryptic peptide reference data sets for MALDI imaging mass spectrometry on formalin-fixed ovarian cancer tissues. J Proteome Res 12: 308-315, 2013

143. Cazares LH, Troyer D, Mendrinos S, et al: Imaging mass spectrometry of a specific fragment of mitogen-activated protein kinase/extracellular signal-regulated kinase kinase kinase 2 discriminates cancer from uninvolved prostate tissue. Clin Cancer Res 15: 5541-5551, 2009. 